\title{
SIGNIFICAÇÕES DO CORPO NA ESCOLA DE APLICAÇÃO DA UFPA
}

\author{
Margarida do Espírito Santo Cunha Gordo' \\ Lívia Maria Neves Bentes² \\ Raiana de Oliveira Alameida ${ }^{3}$
}

\section{RESUMO}

Ao nos lançarmos neste processo investigativo com o objetivo de compreender as significações construídas sobre e pelo corpo junto aos alunos da escola básica, colocamo-nos ao mesmo tempo o compromisso de refletir sobre a forma como as práticas escolares, como extensões de nossas atividades humanas vem incidindo nas atribuições de sentido que os alunos fazem do corpo. Ancoramos nossa metodologia em uma abordagem qualitativa e para a coleta e a análise dos dados, no que diz respeito ao discurso dos alunos, utilizamos a Técnica de Elaboração e Análise de Unidades de Significado proposta por Moreira, Simões e Porto (2005). A partir da pergunta geradora: o que significa a palavra corpo para você? Identificamos quatro unidades de significado: 1) corpo biológico; 2) corpo reprodutor; 3) movimento; 4) morada da alma. A análise dos resultados nos levaram a inferir que as significações atribuídas pelos doze sujeitos da pesquisa ainda permanecem fortemente atreladas a uma visão utilitarista, instrumental e fragmentada do corpo. Ao nos depararmos com este cenário, defendemos a corporeidade como o elo fundamental a ser trabalhado dentro da escola com o intuito de restituir a concepção de unidade corpórea e a noção de corpo como a manifestação de nossa própria existência.

Palavras-chave: Corpo. Significação. Escola.

\section{IGNIFICATIONS OF THE BODY AT THE UFPA APPLICATION SCHOOL}

\begin{abstract}
As we embark on this investigative process with the goal to understand the construction of meanings on and by the body amongst students of primary and secondary school, we are at the same time committed to reflect on how school practices, as extensions of our human activities, affect the attributions of meaning

1 Doutora em Educação pela UNICAMP, coordenadora de projeto no PIBIC/UFPA e professora de Educação Física da Escola de Aplicação da UFPA. E-mail: margaridagordo@yahoo.com.br

2 Mestranda do Programa de Pós-Graduação em Currículo e Gestão de Escola Básica da UFPA e professora de Educação Física da Escola de Aplicação da UFPA. E-mail: livia.bentes@hotmail.com

3 Graduanda em Educação Física pela Universidade Federal do Pará e bolsista do PIBIC/UFPA. E-mail: raianaoliveira.1994@gmail.com
\end{abstract}


that the students make of the body. We have anchored our methodology in a qualitative approach and for data collection and analysis, with regard to student discourse, we used the Technique of Elaboration and Analysis of Units of Meaning proposed by Moreira, Simões and Porto (2005). From the generating question: what does the word body mean to you? We identified four units of meaning: 1) biological body; 2) reproductive body; 3) movement; 4) the abode of the soul. The analysis of the data led us to infer that the meanings attributed by the twelve subjects of the research still remain strongly tied to a utilitarian, instrumental and fragmented view of the body. When we come across this scenario, we defend corporeity as the fundamental link to be worked within the school in order to restore the conception of corporeal unity and the notion of body as the manifestation of our own existence.

Keywords: Body. Significance. School.

\section{SIGNIFICACIONES DEL CUERPO EN LA ESCUELA DE APLICACIÓN DE LA UFPA}

\section{RESUMEN}

Al lanzarnos en este proceso investigativo con el objetivo de comprender las significaciones construidas sobre y por el cuerpo junto a los alumnos de la escuela básica, nos comprometimos al mismo tiempo a reflexionar sobre la forma en que las prácticas escolares, como extensiones de nuestras actividades humanas vienen incidiendo en las atribuciones de sentido que los alumnos hacen del cuerpo. Anclamos nuestra metodología en un abordaje cualitativo y para la recolección y el análisis de los datos, en lo que se refiere al discurso de los alumnos, utilizamos la Técnica de Elaboración y Análisis de Unidades de Significado propuesta por Moreira, Simões y Porto (2005). A partir de la pregunta generadora: qué significa la palabra cuerpo para usted? Identificamos cuatro unidades de significado: 1) cuerpo biológico; 2) cuerpo reproductor; 3) movimiento; 4) morada del alma. El análisis de los resultados nos llevaron a inferir que las significaciones atribuidas por los doce sujetos de la investigación todavía permanecen fuertemente ligadas a una visión utilitarista, instrumental y fragmentada del cuerpo. Al encontrarse con este escenario, defendemos la corporeidad como el eslabón fundamental a ser trabajado dentro de la escuela con el propósito de restituir la concepción de unidad corpórea y la noción de cuerpo como la manifestación de nuestra propia existencia.

Palabras clave: Cuerpo. Significación. Escuela.

\section{INTRODUÇÃO}

Dizer da história do corpo é o mesmo que dizer da história da vida (SANT' ANNA, 2004, p. 3).

Há questões muito pertinentes sobre o corpo que necessitam de reflexão e discussão dentro do ambiente escolar, como as levantadas por Barbosa; Matos; Costa (201 1, p. 24) "Quem somos nós, humanos? O que é ser 
um corpo? O que é ter um corpo? O que é hoje a nossa corporeidade? Quais possibilidades nos são abertas e, que experiências nos são possíveis?"

Todos estes questionamentos são fundamentais, não apenas pela dimensão problematizadora que a escola do século XXI precisa tomar para si, mas também porque nos fazem atribuir sentidos essenciais para a formação humana em todas as suas dimensões, como a cultural, social, intelectual, ética entre outras que compõem esse processo.

Segundo Probst e Kraemer (2012) desde a sua fundação no século XIX, a escola assumiu o lugar de instrução dos indivíduos, assentando-se ao longo da história, em práticas pedagógicas que se constituíram como elementos de modulação do corpo e que estão presentes ainda hoje. Nesta perspectiva, ultrapassou seu papel voltado para o desenvolvimento intelectual e, consolidada como uma das mais importantes instituições da era moderna, passou a engajar-se no direcionamento dos ideais disciplinadores e de controle para atender as convenções vigentes na sociedade e, salvaguardar o status quo.

De acordo com Foucault (2014) a escola está entre as instituições que mais investiram no controle e manipulação do corpo impondo a disciplina, como um dos principais métodos para dar respostas às conjunturas de poder de cada época. Sobre a questão, o autor aponta que:

O momento histórico das disciplinas é o momento em que nasce uma arte do corpo humano, que visa não unicamente o aumento de suas habilidades, nem tampouco aprofundar sua sujeição, mas a formação de uma relação que no mesmo mecanismo o torna tanto obediente quanto mais útil $e$, inversamente. Forma-se então uma política das coerções que são um trabalho sobre o corpo, uma manipulação calculada de seus elementos, de seus gestos, de seus comportamentos. O corpo humano entra numa maquinaria de poder que os esquadrinha, o desarticula e o recompõem (p. 135).

Outra característica importante que foi incorporada pela escola, ao longo do tempo, foi a compartimentalização excessiva do saber e a percepção fragmentada da realidade, no contexto disciplinar da escola. Para Morin (2011) a hiperespecialização das ciências como disciplinas, gera o seguinte: 
[...] as realidades globais e complexas, fragmentam-se; o humano desloca-se; sua dimensão biológica, inclusive o cérebro, é encerrada nos departamentos de biologia; suas dimensões psíquica, social, religiosa e econômica são, ao mesmo tempo, relegadas e separadas umas das outras, nos departamentos de ciências humanas; seus caracteres subjetivos, existenciais, poéticos encontram-se confinados nos departamentos de literatura e poesia. A filosofia, que é por natureza a reflexão sobre qualquer problema humano, torna-se, por sua vez, um campo fechado sobre si mesmo (p. 37).

Estes dois aspectos que trazemos à tona, a modulação do corpo para o controle social e a fragmentação do conhecimento apresentam-se hoje entre os grandes pilares que conduzem os processos educativos no interior das instituições escolares, incidindo de maneira direta sobre a dinâmica da percepção e da significação do corpo.

Nesta perspectiva, o fenômeno da significação não se aparta do corpo e da existência, mas emerge nas e das experiências com o corpo, sendo a escola uma das principais instituições sociais responsável pela construção deste fenômeno (NÓBREGA, 2010). Assim, lançamo-nos nesta investigação com o intuito de conhecer as significações construídas sobre e pelo corpo, junto aos alunos da escola básica.

Neste artigo, fruto de uma pesquisa realizada na Escola de Aplicação da Universidade Federal do Pará, realizamos um sobrevoo sobre as marcas e representações cunhadas no corpo ao longo do tempo. Assim, nos reportamos ao corpo primitivo; ao que Sócrates, Platão e Aristóteles pensavam sobre o corpo; o corpo medieval; o corpo moderno e o corpo contemporâneo. Em seguida apresentamos os caminhos seguidos pela pesquisa para a construção deste artigo. A partir daí os resultados obtidos são expostos e entrelaçados com o que diz a literatura sobre as quatro unidades de significado captadas das respostas dos alunos à pergunta geradora, de acordo como indica a Técnica de Elaboração e Análise de Unidades de Significado proposta por Moreira, Simões e Porto (2005).

\section{As marcas históricas no corpo}

Para iniciarmos nossa incursão sobre o corpo é imprescindível realizar um sobrevoo para observar como o corpo vem sendo tratado ao longo da 
história. Recorreremos, portanto, a alguns momentos históricos, sem delimitações rigorosas de datas ou períodos, mas buscando breves descrições dos traços no corpo que se destacaram em períodos marcantes, visando compreender e reconhecer as nuances do corpo, como sujeito histórico.

A história do corpo confunde-se com a história da civilização. Haja vista que o corpo pode ser considerado como produto de cada cultura, de cada sociedade, as quais o determinam, o delineiam, construindo suas particularidades, dando ênfase para umas características em detrimento de outras, cunhando modelos particulares para cada corpo, surgindo, desta forma, os padrões que marcam nossa sociedade: beleza, saúde, postura. Estes padrões, muitas vezes, determinam a construção dos indivíduos como homens e mulheres (BARBOSA; MATOS; COSTA, 2011).

Esses padrões, ao longo do tempo, foram imprescindíveis para a produção da história do corpo, funcionando como mecanismos codificadores de sentido. Para Ferreira (2008, p. 472) "o corpo é socialmente construído e nele se materializa a relação sujeito x sociedade, tornando-se a arena onde acontecem os conflitos simbólicos que refletem questões do nosso tempo".

O corpo ganhou a atenção de várias áreas da Ciência e da Filosofia, ao incorporar um discurso interdisciplinar, muito provavelmente pelas transformações sofridas ao longo da construção da sociedade ocidental que despertou o interesse em discuti-lo e estudá-lo com mais profundidade (CASSIMIRO; GALDINO; MATEUS DE SÁ, 2012).

De acordo com Costa (2011) mesmo parecendo contraditório, o Homem primitivo é considerado como único e original, no que diz respeito ao modo de viver no ambiente, percebendo-se como parte desse ambiente. Essa relação torna-se evidente nos desenhos rupestres localizados em sítios arqueológicos encontrados em todos os continentes.

Assinala Costa (2011, p. 247) que "os trabalhos rupestres mostram a representação de corpo do homem primitivo, deles emergindo a sua 
relação mítica com o mundo que o cerca". Ressalta ainda a autora que os desenhos rupestres que expressam as posturas e posições corporais, revelam como os homens primitivos concebiam o corpo.

Apesar da política e a ética serem o foco dos pensadores na Grécia Antiga, o corpo também tinha seu espaço de discussão com Sócrates (470 a 399 a.C.), Platão (427 a 347) e Aristóteles (384 a 322 a.C.). Sócrates tinha uma visão integral de homem, corpo e alma tinham igual valor para a integração do homem com o mundo. A visão de Platão era dicotômica, corpo e alma tinham valências diferentes, sendo o corpo considerado uma prisão para a alma. Já Aristóteles aproximava seu pensamento com o de Sócrates, por pensar as ações humanas executadas em conjunto, corpo e alma, unidos num processo contínuo de realização (BARBOSA; MATOS; COSTA, 2011). O fato é que esses filósofos apresentaram abordagens que definiram o cerne das concepções de corpo da sociedade ocidental ao longo de sua formação, pois tentaram explicar e entender a construção social, cultural e histórica vividas pelo corpo.

A Idade Média foi um período de mortificação e desprezo pelo corpo. As instituições religiosas, sob a bandeira do cristianismo, com a tutela da monarquia, incentivavam o cultivo por um corpo extremamente contido, restringindo qualquer manifestação criativa do homem, promovendo rigidez dos valores morais e uma nova concepção de corpo. Delineando-se aí a separação do corpo com a alma, prevalecendo a alma sobre o corpo (BARBOSA; MATOS; COSTA, 2011). Uma retomada ao pensamento de Platão.

Depois desse aprisionamento do corpo veio a Era Moderna com o Renascimento. Da Vinci e Michelangelo com a arte da pintura, contribuíram muito para a fase de redescoberta do corpo. Segundo Barbosa; Matos; Costa (2011) nesse período da história houve uma mescla entre arte e ciência no que diz respeito ao estudo do corpo, tendo sido o método científico o guia das ações humanas. Apesar da expressão artística tomada pelo corpo, este passou a ser objeto de estudos e experiências científicas, sendo minuciosamente descrito e analisado em sua anatomia e 
biomecânica (GAYA, 2005). Essa divisão dicotômica do corpo iniciada por Platão e referendada na Idade Média, foi recebida e fortemente promovida por René Descartes com a divisão corpo-mente, sendo o corpo todo fracionado para estudos e seu funcionamento comparado a uma engrenagem de relógio (CAPRA, 1993), estando este a serviço da razão.

Já na contemporaneidade "o corpo pós-moderno passou do mundo dos objetos para a esfera do sujeito, assumido e cultivado como um 'eucarne', credor de reconhecimento e de glorificação, e mesmo objeto-sujeito de culto" (RIBEIRO, 2003, p. 7). A mídia tem sido uma grande protagonista ao ditar padrões de beleza do corpo, fomentando uma rede de consumo e de intervenção, inclusive cirúrgica do corpo. O corpo contemporâneo é um corpo livre? É um corpo pleno? As marcas culturais incrustadas no corpo há milênios se apartaram desse corpo contemporâneo?

Essa centralidade assumida pelo corpo revela muito mais do que o próprio corpo, ela é carregada de valores simbólicos e age como demarcadora de sua identidade cultural. Como o corpo é o primeiro contato do ser humano com tudo e com todos que o cerca, nele é delineado o arcabouço cultural de um grupo específico. Daolio (2009, p. 39) reforça esse pensamento quando diz que "o corpo é a expressão da cultura, portanto cada cultura vai se expressar por meio de diferentes corpos, porque se expressa diferentemente como cultura".

Seguindo essa linha, é relevante mencionar que corpo e cultura mantêm uma interdependência. A cultura precisa do corpo para se materializar, se mostrar, se fazer presente. Assim como o corpo precisa da cultura como instrumento de civilidade, de socialização e de educação, tomando-se o cuidado, como alerta Csordas (1990), para que o corpo não seja reduzido a um objeto a ser estudado em relação à cultura.

O corpo humano não se traduz apenas por seu aspecto puramente biológico, sobre o qual a cultura impinge especificidades, o corpo é fruto da interação entre natureza e cultura e, conceber o corpo como meramente biológico é pensá-lo como natural, e como consequência desse 
pensamento, entender que a cultura é um processo posterior ao desenvolvimento do ser humano, uma mera coadjuvante e, não que a cultura seja a grande responsável por esse desenvolvimento (GEERTZ, 2008).

De acordo com Le Breton (2009, p. 11 ) apesar do corpo representar o principal ponto de diferenciação entre as pessoas e por marcar a individualidade de cada um, acredita, que parte dele a ligação entre outros corpos, ou seja, o corpo é o lócus das relações interpessoais, "o conector que o une aos outros".

Toda essa discussão e entendimento sobre o corpo faz-se necessária na escola. Nos papeis de professoras de Educação Física da Educação Básica e de graduanda nessa área, percebemos uma dificuldade muito grande desses estudos adentrarem a escola. Como constatamos em nossas vivências, algumas vezes esses estudos até conseguem transpor o muro físico, porém, os muros ideológicos continuam inabalados, ou seja, fala-se de corpo para os alunos até como parte obrigatória de conteúdo, mas essas teorias, na maioria das vezes, não produzem conhecimentos, não promovem transformações nos discentes e nem na comunidade escolar, não os possibilitando que se reconheçam como corpo-sujeito (LOURO, 2000a).

Inforsato (2006, p. 102) ressalta que a organização escolar que alija o corpo da interação com o mundo "não se cumpriv e nem se cumpre à risca. O movimento próprio da sociedade, transportando toda a sua complexidade - atavismos, tradições e outros fatores dinâmicos - deu tons vários para a escola". Porém, assinala ainda (p. 103) que mesmo a "despeito desse ímpeto reformista a escola tradicional mantém seu domínio e ainda resiste bravamente às investidas que querem flexibilizá-la".

Como acrescentam Quadrado e Ribeiro $(2005$, p. 3) a escola ainda é comprometida em manter o status quo, ela está imersa em uma sociedade que exige essa função dela, desta forma, "tem um papel de destaque na produção de representações sobre o corpo, produzindo valores e saberes, regulando condutas e modos de ser e fabricando identidades e representações" por meio de seu currículo e de suas práticas cotidianas. 
Esta pesquisa buscou compreender o entendimento dos alunos do $6^{\circ}$ ano do Ensino Fundamental maior sobre o corpo. Que corpo é o seu? Um corpo máquina? Um corpo sujeito? Um corpo biológico? Qual sentido dá ao seu corpo? Que corpo ou qual sentido de corpo está sendo construído na escola?

Com esta diagnose abrimos possibilidades de reflexão sobre o tema, trabalhando em prol da construção de um corpo-sujeito, valorizando mais as experiências e a cultura impressa no corpo de cada aluno. Pois, "no corpo estão inscritas todas as regras, todas as normas e todos os valores de uma sociedade específica, por ser ele o meio de contato primário do indivíduo com o ambiente que o cerca" (DAOLIO, 2009, p. 105). Precisamos aprender a ouvir, a ler, a entender esse corpo sujeito, esse corpo que é biológico, é social, é cultural. Esse corpo que é o próprio ser humano, que é a própria existência humana.

\section{MATERIAIS E MÉTODOS}

A pesquisa foi embasada na perspectiva qualitativa, que segundo Neves (1996) possibilita um contato direto e interativo entre o pesquisador e o objeto pesquisado e, se vale da interpretação do fenômeno, levando em consideração toda sua subjetividade, com o intuito de decodificar e de revelar sua complexidade.

Para a coleta e a análise dos dados, no que diz respeito ao discurso dos alunos, utilizamos a Técnica de Elaboração e Análise de Unidades de Significado (MOREIRA, SIMÕES e PORTO, 2005). Essa técnica consiste na adaptação de uma combinação da Análise de Conteúdo, a Análise de Avaliação Assertiva de Bardin (1977) e a Análise do Fenômeno Situado de Giorgi (1978) e Martins e Bicudo (1989). Ela é composta por três momentos: 1) Relato Ingênuo - é a resposta a uma pergunta geradora; 2) Identificação de Atitudes - seleção das unidades mais significativas dos discursos dos sujeitos; 3) Interpretação - análise interpretativa do fenômeno estudado.

Os sujeitos da pesquisa foram 12 alunos, matriculados regularmente no $6^{\circ}$ ano do Ensino Fundamental Maior, da Escola de Aplicação da 
Universidade Federal do Pará. A escola possui quatro turmas de $6^{\circ}$ ano, cada uma com uma média de 30 alunos por turma, com faixa etária entre 12 e 13 anos. Seguindo procedimentos éticos, por se tratarem de sujeitos menores de idade, encaminhamos o Termo de Consentimento Livre e Esclarecido (TCLE) aos responsáveis legais de cada um deles.

Do universo de cerca de 120 alunos para os quais foram encaminhados os TCLE, 12 devolveram o referido termo devidamente preenchido e assinado, junto aos quais foi aplicada a pergunta geradora. As pesquisadoras levaram os doze alunos para uma sala de aula da Escola de Aplicação, os quais tiveram um tempo de até cinquenta minutos para responderem a seguinte pergunta: o que significa a palavra corpo para você?

Para preservar a integridade e a identidade dos sujeitos participantes, os identificamos por números de 01 a 12. Ressaltamos que devido a alguns erros de grafia e de concordância na escrita dos alunos, com o intuito de mantermos um texto limpo, realizamos a correção gráfica e gramatical de tais palavras e expressões em suas respostas.

\section{RESULTADOS E DISCUSSÃO}

A partir da pergunta geradora: o que significa a palavra corpo para você?, identificamos quatro unidades de significado: 1) corpo biológico; 2) corpo reprodutor; 3) movimento; 4) morada da alma, as quais estão representadas no quadro 1 , indicando os pontos de convergência e de divergência como estabelece a técnica.

Quadro 1: Unidades de significado da pergunta geradora.

\begin{tabular}{|l|l|l|l|l|l|l|l|l|l|l|l|l|l|c|}
\hline \multicolumn{1}{|c|}{ Sujeitos } & & & & & & & & & & & & & $\begin{array}{l}\text { T } \\
\text { O } \\
\text { T }\end{array}$ & \\
$\begin{array}{l}\text { Unidades } \\
\text { de } \\
\text { Significado }\end{array}$ & 1 & 2 & 3 & 4 & 5 & 6 & 7 & 8 & 9 & 10 & 11 & 12 & $\mathrm{~A}$ & $\%$ \\
\hline Corpo biológico & $\mathrm{X}$ & $\mathrm{X}$ & $\mathrm{X}$ & $\mathrm{X}$ & $\mathrm{X}$ & $\mathrm{X}$ & $\mathrm{X}$ & $\mathrm{X}$ & $\mathrm{X}$ & $\mathrm{X}$ & $\mathrm{X}$ & & 11 & 91,6 \\
\hline
\end{tabular}




\begin{tabular}{|l|l|l|l|l|l|l|l|l|l|l|l|l|l|r|}
\hline $\begin{array}{l}\text { Corpo } \\
\text { reprodutor }\end{array}$ & & & & X & & & X & X & & & X & X & 5 & 41,66 \\
\hline Movimento & X & & & & & & & & & X & X & & 3 & 25 \\
\hline $\begin{array}{l}\text { Morada da } \\
\text { Alma }\end{array}$ & & & & X & & & & & & & & X & 2 & 16,66 \\
\hline
\end{tabular}

Fonte: Produzido pelas pesquisadoras como indica a técnica.

Fazendo uma análise do quadro acima, constatamos um alto percentual de convergência, 91,6\% para a unidade de significados corpo biológico. Dos 12 (doze) alunos que participaram da pesquisa, 11 (onze) responderam que a palavra corpo significa órgãos, células, neurônios, músculos, ossos e etc.

Como observamos na fala do aluno 07 (sete): "para mim, nosso corpo é formado por vários membros e ossos de diferentes tamanhos. O nosso corpo também é formado por órgãos diversos, como coração, pulmão, fígado, esôfago, pâncreas e etc. Dentro do nosso corpo tem muita água, a quantidade de água é uns $70 \%$. Também dentro dele existe muitas veias e é cheio de circulação sanguínea".

O aluno 06 segue a mesma perspectiva do anterior no seu entendimento sobre corpo: "Eu entendo sobre o corpo que tem vários órgãos: olhos, uma boca, braços, pernas, mãos e ouvido. Para mim esses são os mais importantes". Ainda nesse sentido o aluno 09 (nove) revela: "meu corpo é composto por ossos que são praticamente a base de tudo, eu só sei como se chamam os dois mais importantes, o fêmur e a coluna vertebral. Na verdade, minha face é composta por dois olhos, duas orelhas, cabelos, um nariz, uma boca, sobrancelhas, pálpebras, cilios, narinas".

Estes alunos revelam em sua fala uma visão de corpo puramente biológico, dando ênfase às divisões anatômicas. Isso pode ser resultado da forma como as disciplinas que tratam do corpo de forma mais específica em seus conteúdos, nesse nível de ensino, como a Ciências e a Educação Física, vêm trabalhando a produção de conhecimento acerca do corpo. 
Ao concentrarmos as análises a partir de nossa área de conhecimento: a Educação Física; observamos que ainda existe a predominância de uma vertente biológica, que aborda o corpo em uma perspectiva mecanicista, não contemplando o ser humano de forma integral, nem os vários sentidos, signos e significados do corpo em diferentes contextos e culturas. Além disso, também existem outros fatores influenciadores para essa visão como: família, mídia, meio social, que ainda hoje, tratam o corpo sob uma ótica instrumental ou funcionalista.

Ao restringir a noção de corpo, associando-a unicamente à anatomia e à fisiologia, a Educação Física escolar acaba contribuindo para o reforço e perpetuação de uma racionalidade instrumental que limita, tanto a concepção, quanto as próprias possibilidades de experimentações do corpo, considerando que as práticas corporais foram e continuam sendo fortemente influenciadas pelos conceitos sobre o corpo (RODRIGUES, 2008).

Além disso, a ênfase em uma visão marcada pelo reducionismo e pelo dualismo, desconecta o ser biológico do ser social; e submerge o entendimento de que nosso corpo é fruto da construção histórica e cultural em que nos inserimos, o que nos coloca distantes da perspectiva de que esta construção cultural do corpo está profundamente enraizada na natureza política da vida em sociedade, que por sua vez está imbricada em relações de poder (MENDES, 2002; NÓBREGA, 2010).

Estas relações de poder, por sua vez, manifestaram-se e manifestam-se de diferentes maneiras, em diferentes contextos, dependendo do tempo e do espaço. Segundo Oliveira (2006) a história nos mostra que a negação do corpo em seu sentido amplo e multidimensional, vivida principalmente dentro da escola contém as marcas de uma sociedade permeada por instrumentos de dominação. Segundo o autor,

[...] O controle sobre o corpo apresentou diferentes facetas que deixaram traços profundos na organização de nossa vida social. [...] se antes o corpo era almejado pelo seu potencial produtivo, agora as atenções se voltam principalmente aos interesses de consumo e exibição (p. 58). 
Diante disso, acreditamos na necessidade de discutir o corpo em suas várias dimensões - biológica, social, cultural, ética, étnica, econômica dentre outras que o fazem existir - no ambiente da escola, o compreendendo como a própria existência humana, o ser, o indivíduo, o cidadão que habita este mundo e, neste sentido, precisa estar munido da capacidade de perceber, criticar e experienciar esse mundo de forma plena.

Esta necessidade de trazer um olhar crítico e abrangente sobre 0 corpo, por meio da busca pela superação de uma concepção predominantemente biológica-instrumental nas aulas de Educação Física, já vem aparecendo em documentos oficiais. Os Parâmetros Curriculares Nacionais - PCNs (BRASIL, 1998, p. 29) apontam para o desenvolvimento de abordagens pedagógicas voltadas para "as dimensões cultural, social, política e afetiva, presentes no corpo vivo, isto é, no corpo das pessoas que interagem e se movimentam como sujeitos sociais e cidadãos" que são.

A Base Nacional Comum Curricular - BNCC (BRASIL, 2017), documento mais recente que norteará a Educação Básica no Brasil, nos itens 2, 3 e 8 demonstram um trato especial com as dimensões citadas nos PCNs:

2. Planejar e empregar estratégias para resolver desafios e aumentar as possibilidades de aprendizagem das práticas corporais, além de se envolver no processo de ampliação do acervo cultural nesse campo.

3. Considerar as práticas corporais como fonte de legitimação de acordos e condutas sociais, e sua representação simbólica como forma de expressão dos sentidos, das emoções e das experiências do ser humano na vida social.

8. Reconhecer as práticas corporais como elementos constitutivos da identidade cultural dos povos e grupos, com base na análise dos marcadores sociais de gênero, geração, padrões corporais, etnia, religião.

Desta forma, podemos observar um esforço na direção do redimensionamento do olhar sobre o corpo, no contexto das práticas e das abordagens da Educação Física na Educação Básica. O viés biológico abrangendo a anatomia e a fisiologia - não deve ser suprimido, porém, há outros vieses não menos importantes, evidenciados tanto pelos PCNs, quanto 
pela BNCC, que comtemplam o corpo a partir das perspectivas cultural e social, das representações simbólicas, que são fundamentais para construção da identidade dos sujeitos. Assim,

A primeira questão que se impõe ao tratarmos do tema "corpo", considerando-o em diferentes aspectos e dimensões, é a necessidade de aceitarmos a condição de que somos sujeitoscorpos, isto é, entendermos o corpo como nossa identidade, nossa unidade de existência que nos dá visibilidade e acesso ao mundo. Está contida nessa concepção a ideia de que, em toda e qualquer ação que realizamos, é possível verificar três dimensões explícitas: biológica, psicológica e social, assim como dimensões implícitas, absolutamente interdependentes das anteriores: antropológicas, econômicas, históricas, entre outras (FARAH, 2010, p. 402).

Nesta perspectiva, "conceber o corpo como meramente biológico é pensá-lo - explícita ou implicitamente - como natural e, consequentemente, entender a natureza do homem como anterior ou pré-requisito da cultura" (DAOLIO, 2009, p. 41). É situação sine qua non para a Educação Física escolar, entender o corpo como uma construção dialógica entre natureza e cultura. Daolio (2009, p. 41) ressalta ainda que "o corpo humano não é um dado puramente biológico sobre o qual a cultura impinge especificidades". O corpo revela muito mais do que o próprio corpo, ele é carregado de valores simbólicos e age como demarcador de sua identidade cultural.

O desafio se apresenta para os educadores, principalmente, para os professores de Educação Física em desmitificar o corpo predominantemente pelo aspecto biológico como sendo a mais importante das significações, dando subsídios para se pensar num corpo que contenha particularidades do sujeito, que permitam a intercomunicação com a singularidade do outro indivíduo, ou seja, com outro corpo.

Dos 12 (doze) alunos que responderam à pergunta geradora, cinco deles, que corresponde a $41,66 \%$ entendem o corpo como corpo reprodutor, o que se encontra explícito nas palavras do aluno 04 (quatro): "o corpo foi criado para reproduzir um embrião, como diz na Bíblia: Deus tirou um pedaço da costela de Adão e reproduziu a Eva porque Adão se sentia só". O aluno 12 (doze) reforça esse pensamento afirmando que: no início do 
mundo foi feito o homem e depois a mulher, o homem tem o seu órgão de reprodução e a mulher também, juntando esses dois órgãos forma um bebê. Para mim corpo foi feito para reproduzir, criar novos descendentes na terra, para reproduzirem e criarem novas nações". De acordo com o aluno 11 (onze): "A missão do corpo (pessoa) é reproduzir e fazer um filho".

Apesar de termos classificado o corpo reprodutor como uma unidade de significados, observamos uma estreita relação dele, tanto com o corpo biológico - ao mencionar os órgãos reprodutores - quanto com os escritos bíblicos, sendo assim, com a religiosidade, que se manifesta a partir das referências às narrativas de Adão e Eva, os dois primeiros seres humanos do mundo (de acordo com o ideário religioso e desses alunos).

Ao defender o corpo como instrumento exclusivo para criação de novos descendentes, a noção de corpo apresentada na fala dos alunos afasta-se de um aspecto fundamental quando tratamos do corpo-sujeito: a identidade; desconsiderando, assim, o processo contemporâneo de constituição das diferentes identidades individuais, sociais e familiares que vêm se apresentando nesse novo século.

De acordo com Louro (2000b), a imutabilidade e a cristalização de alguns setores da nossa sociedade, vêm desde a década de 1960 sofrendo fortes abalos em sua estrutura, devido ao surgimento de novas identidades sociais, o que suscita uma nova ordem social. Como podemos observar:

As novas tecnologias reprodutivas, as possibilidades de transgredir categorias e fronteiras sexuais, as articulações corpo-máquina a cada dia desestabilizam antigas certezas; implodem noções tradicionais de tempo, de espaço, de "realidade"; subvertem as formas de gerar, de nascer, de crescer, de amar ou de morrer. Jornais e revistas informam, agora, que um jovem casal decidiu congelar o embrião que havia gerado, no intuito de adiar 0 nascimento de seu filho para um momento em que disponha de melhores condições para criá-lo; contam que mulheres estão dispostas a abrigar o sêmen congelado de um artista famoso já morto; revelam a batalha judicial de indivíduos que, submetidos a um conjunto complexo de intervenções médicas e psicológicas, reclamam uma identidade civil feminina para completar o processo de transexualidade que empreenderam. Conectados pela Internet, sujeitos estabelecem relações amorosas que desprezam dimensões de espaço, de tempo, de gênero, de sexualidade e estabelecem jogos de identidade múltipla nos quais o anonimato e a troca de

Revista Exitus, Santarém/PA, Vol. 8, № 2, p. 329 - 357, MAl/AGO 2018. 
identidade são frequentemente utilizados. Embaladas pela ameaça da AIDS e pelas possibilidades cibernéticas, práticas sexuais virtuais substituem ou complementam as práticas face-a-face. Por outro lado, adolescentes experimentam, mais cedo, a maternidade e a paternidade; uniões afetivas e sexuais estáveis entre sujeitos do mesmo sexo se tornam crescentemente visíveis e rotineiras; arranjos familiares se multiplicam e se modificam... (LOUROb, 2000, p. 5)

Diante de toda essa visível e veloz transformação que vem ocorrendo em nossa sociedade, motivada por demandas individuais e sociais reprimidas há séculos, ao nos depararmos com a resposta de alunos que enxergam o corpo como reprodutor e principalmente, com identidades individuais e sociais inertes, dentro de uma sociedade e de um estilo de vida em transformação, nos perguntamos: por que a escola do século XXI continua se mantendo com pés firmes em séculos passados? Para qual direção nós professores estamos levando, fixando ou retrocedendo as mentalidades dos nossos alunos? Que corpo é esse que estamos apresentando ou representando para os nossos alunos? Como ressalta Louro (2000b, p. 60), "o corpo parece ter ficado fora da escola".

Dos 12 (doze) alunos participantes da pesquisa, 03 (três) deles, que corresponde a $25 \%$, responderam que corpo significa movimento. $O$ aluno 1 (um) destaca: "corpo para mim é uma coisa muito importante, porque com o corpo nós podemos nos movimentar, se não nos movimentarmos, não fazemos nada. Imaginem como ficaríamos sem o movimento do nosso corpo. De acordo com o aluno 11 (onze): "o corpo é o meio pelo qual nos movimentamos, praticamos esportes e fazemos coisas".

Quando analisamos a concepção de corpo relacionada ao movimento, na fala dos alunos, observamos uma relação de interdependência, na qual o corpo serve para movimentar-se, serve para realizar práticas cotidianas. Embora demonstre uma noção mais abrangente de corpo, trazendo à tona um elemento fundamental para a constituição da vida humana: o movimento; a fala dos alunos ainda não rompe totalmente com uma ideia utilitarista do corpo.

É fundamental compreendermos que a relação corpo-movimento não se trata simplesmente de usar o corpo como um instrumento para realizar 
determinada ação, mas sim, como aponta Nóbrega (2005, p. 607), de "enfatizar a vivência do corpo em movimento como campo criador de sentidos". Ou seja, as produções humanas não abrangem tão somente a objetividade de uma ação fechada em si. O movimento, como expressão da atividade humana, sempre estará carregado de intencionalidades que partem da percepção e das significações de cada sujeito, nos diferentes contextos, espaços e tempos.

Sendo assim, o ser humano não pode ser concebido como um corpo estanque e servil, por ser transitório, diverso, intencional, subjetivo e, este entendimento traduz a manifestação da corporeidade. A corporeidade agrega os elementos que formam a estrutura básica de nossa existência humana: movimento, percepção e conhecimento. Com base ns estudos em Merleau-Ponty e Varela, Nóbrega (2005) nos revela que o sentido do corpo em movimento, configura uma percepção que, ao interpretar a realidade, por meio da motricidade, desloca o sujeito como epicentro do conhecimento, privilegiando a complexidade dos esquemas corporais. Neste sentido, a cognição, o processo de conhecer dependerá da experiência que acontece na ação corporal.

A corporeidade, desta forma, vai de encontro com a noção utilitarista do corpo que serve para um fim ou serve a uma condição determinada, engessado como instrumento. Ela assenta suas bases em uma concepção existencialista do corpo, em que a sensibilidade, a capacidade de percepção do corpo se estabelece como uma potência de conhecimento, evidenciando que a existência é primeiramente corporal e, sendo o corpo nossa própria experiência no mundo, ele é a referência primeira do conhecimento (NÓBREGA, 2010).

Ao entrarmos no universo escolar, Nista-Piccolo e Moreira (2012a) defendem que a ideia de corporeidade, associada ao corpo ativo, ao corpo em movimento requer considerar a educação como uma experiência profundamente humana, sendo o corpo compreendido a partir de sua integração na estrutura global. Para tanto, a corporeidade exige uma 
aprendizagem significativa da cultura. Esta aprendizagem significativa pressupõe que "o conhecimento torna-se indispensável para a vida quando o transformamos em sabedoria, ou seja, em conhecimento experimentado, saboreado, incorporado" (NISTA-PICCOLO e MOREIRA, 2012b, p. 6).

Os autores apontam ainda que muitas vezes a escola acaba se tornando desinteressante porque não apresenta o conhecimento na dimensão das experiências, das vivências. Destacam que a escola, ao longo da história, foi extremamente eficiente em criar corpos inativos e aprendizagens segmentadas, priorizando o intelecto e negando o corpo.

Essa negação do corpo se deu e ainda acontece por meio de inúmeros mecanismos de controle do comportamento - como a negação do corpo sujeito e supervalorização do corpo objeto e a concepção hegemônica de ciência (MOREIRA; SIMÕES; MURIA, 2009); o reforço à "dicotomia corpo/mente, buscando "moldar" corpos "dóceis e úteis", passiveis de acatar e reproduzir as ideologias hegemônicas" (QUADRADO; RIBEIRO, 2005, p. 3), dentre tantos outros mecanismos reforçados pela escola - dentro de uma concepção instrumental, de corpo-recipiente passivo e imóvel, no qual são depositadas informações para serem reproduzidas (STOROLLI, 2011).

Ferracini (2006) nos alerta que ao conceber o corpo como instrumento ou ferramenta, submetemos sua manipulação por algo supostamente superior, ou mais adestrado, ou mais treinado que saiba manipular e usar este instrumento, colocando o corpo na condição de objeto. No âmbito do processo de aprendizagem esta perspectiva nos empurra, ou nos mantém atrelados a uma estrutura moderna e tradicional de educação que se materializa em corpos dóceis, disciplinados, enfileirados, enquadrados em tempos e espaços fora de si mesmos, recebendo informações fragmentadas e afastadas de suas realidades.

Este cenário nos coloca diante da importância da manifestação da corporeidade nos processos educativos, pois ela transcende uma ideia simplista de superação da imobilidade física, entendendo a ação humana 
como processos de significações vividas, na qual o movimento caminha em direção à liberdade de pensar e agir, à possibilidade de experienciar o mundo com as próprias mãos, de sentir o diálogo entre a vida e o conhecimento na pele, estimulados por interesses que partem de dentro de si, do contato com o mundo e com o outro.

Do total de alunos, 16,6\%, que corresponde a 02 (dois) alunos entendem o corpo como a morada da alma. Como mencionado na resposta do aluno 04 (quatro): "corpo para mim é o que guarda a nossa alma, é o que protege o nosso espírito". De acordo com o aluno 12 (doze): "o corpo comete pecado e prejudica a alma. A nossa inteligência vem da alma e do espírito e não do corpo".

A noção explicitada pelos alunos nos remete à compreensão de corpo mais difundida na cultura ocidental: o corpo como instrumento da alma. Esta concepção tem se mostrado, ao longo da história, como uma submissão conceitual ao dualismo psicofísico que divide o ser humano entre o material e o imaterial, subordinando o corpo à alma, o corpo à mente (COSTA, 2011).

Nóbrega (2012) esclarece que por mais que esta dualidade venha nos acompanhando desde a antiguidade até os dias de hoje, as concepções de alma e de corpo foram se transformando neste caminho. Desta forma, a autora aponta que a compreensão de alma na antiguidade grega não era a mesma da visão cristã, assim como a partir da modernidade a ideia de alma ou espírito passou a ser associada à razão ou à mente.

Entre as vertentes que mais influenciaram e perpetuaram uma visão dual de ser humano, duas se destacam: a filosofia cristã e a ciência moderna. A corrente filosófica cristã ganha forma e força no período medieval sobre a égide dos pensamentos de Platão e Aristóteles, incorporados, em certa medida e salvaguardando suas particularidades, pelos filósofos cristãos Santo Agostinho e São Tomás de Aquino.

Santo Agostinho foi um dos grandes representantes da patrística, movimento dos primeiros padres da Igreja que buscaram associar a filosofia 
clássica greco-romana ao cristianismo. Concebia o Homem como um ser divino, criado a imagem e semelhança de Deus, que tinha na racionalidade a grande distinção em relação às coisas da natureza, principalmente aos outros animais. Mesmo tendo superado a ideia de corpo como cárcere da alma, defendida por Platão e, admitindo o corpo como algo bom, por ser uma obra de Deus, defendia a superioridade da alma em relação ao corpo, por entender que a alma carrega a racionalidade do ser. Para Agostinho, a inteligência humana era incorpórea e representava a essência da alma racional, assim:

A alma possui razão e inteligência para, através da ciência e da doutrina, alcançar a percepção da verdade e amar aquilo que entendia por bem, o que consistirá na posse da sabedoria - por extensão, das virtudes - isto é, vencer os vícios. Mas tudo isto deve seguir um fio condutor, o desejo do imutável e soberano Bem: Deus (PIRATELI, 2009, p. 08).

No mesmo escopo da visão de Agostinho, São Tomás de Aquino perpetuou a essência racional da alma em seus escritos. Como o principal representante da escolástica, período de desenvolvimento da filosofia dos doutores da Igreja, dedicou-se à aplicação da razão às questões da fé. Com base no pensamento aristotélico, defendeu que a alma humana é uma substância intelectual unida ao corpo. Assim como Agostinho, não admitia a dicotomia platônica, que desprezava o corpo e o colocava em oposição à alma, mas sim acreditava que corpo e alma eram inseparáveis e interdependentes, já que a alma precisava do corpo para atingir seus fins, enquanto o corpo não existe sem a alma (CAMPOS, 2007).

No entanto, Para Tomás de Aquino o corpo, mesmo necessário, não participava dos processos de intelecção, assim, a alma era considerada o princípio primeiro, o mais profundo; representava a forma imaterial da vida, portanto, incorpórea, enquanto o corpo, material, captava por meio dos sentidos as coisas do mundo (PICLHER, 2008).

Preservando seus contrapontos, ambos concebiam tanto a ideia de unidade entre corpo e alma na composição da natureza humana, quanto a superioridade da alma em relação ao corpo, por ser considerada o sopro 
vital que anima o corpo, detentora de toda a racionalidade, fonte do intelecto do ser humano, enquanto o corpo guarda, recebe, abriga a alma.

Esta hierarquia e sujeição entre corpo e alma foi fortemente perpetuada no pensamento cristão. A essa concepção soma-se ainda a ideia de corpo como símbolo do pecado da carne, associado ao pecado original cometido por Adão, considerado o grande gerador da natureza humana, criada por Deus (SILVA, 2009).

Com a passagem do mundo medieval para o mundo moderno, marcado pela busca do conhecimento racionalista e empirista, certo e evidente, as concepções dualistas de corpo serão assentadas em novos paradigmas. De acordo com Tiriba (2008), durante a época moderna, a discussão sobre o chamado problema da relação entre alma e corpo manteve algumas das concepções antigas e medievais, mas 0 desenvolvimento da ciência em moldes mecanicistas, trouxe a noção de corpo material, radicalmente separado da alma.

Neste período as ideias de René Descartes foram decisivas para o desenvolvimento de uma base orientadora para a ciência moderna, assentada na noção de mundo como uma máquina que avançaria também na compreensão da natureza humana (CAPRA, 1993). Descarte interpretava o Homem a partir de uma clara dicotomia físico-mental. Para o filósofo, as duas substâncias que compõem o ser humano: corpo e alma; são substâncias de natureza completamente distintas, que possuem atributos diferentes e comprovadamente independentes (PINHEIRO, 2011).

A alma para Descartes era concebida como coisa pensante, o pensamento considerado como produto da atividade mental consciente, a substância pensante. A alma era entendida como algo sem materialidade, que não ocupa espaço, nem pode ser mensurada ou quantificada, abrigando uma natureza incorpórea. O corpo era visto e estudado como coisa extensa, possuindo largura, comprimento e profundidade, considerava-o a substância física. Entendia também, suas funções submetidas às leis mecânicas - comparando-as às engrenagens de um 
relógio - produzidas sem qualquer referência ao pensamento (PINHEIRO, 2011).

Segundo Capra (1993), esta concepção de ser humano de Descarte parte do ponto fundamental de seu método de busca pelo conhecimento verdadeiro: a dúvida. Ao duvidar de tudo que pode submeter à dúvida e ao alcançar uma coisa, a qual não pode duvidar: a existência de si mesmo como pensador, o filósofo chega à sua famosa afirmação: Cogito, ergo sum! - Penso, logo existo! Assim, o cogito cartesiano fez com que Descarte privilegiasse a mente em relação à matéria. Defendemos a ideia de que não há nada no conceito de corpo que pertença à mente, nem no conceito de mente que tenha algum efeito sobre o corpo.

Ainda de acordo com Capra (1993), a divisão cartesiana entre corpo e mente, matéria e pensamento atingiu profundamente 0 pensamento ocidental e perpetuou a supervalorização do trabalho mental em relação ao manual; concebeu o ser humano como egos isolados dentro de corpos.

A famosa máxima "penso, logo existo" implica numa concepção que permeia todo o conhecimento e os valores ocidentais, e que tem duas características muito definidas: a de que corpo e mente são opostos, e a de que o corpo é um mero suporte para as nobres atividades mentais. Essa concepção, na escola, se materializa como a crença de que só se aprende com a mente (PENA; BOGÉA; BORGES, p. 29, 2008).

Diante do exposto é possível inferir que tanto o pensamento filosófico cristão, quanto os princípios da ciência moderna, permeados pelas concepções de Descarte, foram cristalizando conceitos que têm contribuído decisivamente para a constituição das formas como nos relacionamos, concebemos, experimentamos e conhecemos o corpo. Não por acaso, quando retomamos os pontos centrais da fala dos alunos, dois aspectos se destacam: a ideia do corpo relacionada ao pecado, vinculada a religiosidade; e a inteligência como algo superior ao corpo.

De forma geral, quando analisamos as quatro unidades de significado desveladas na pesquisa, deparamo-nos com marcas corporais que ainda estão fortemente atreladas a uma visão instrumental e fragmentada do 
corpo. Neste contexto, a escola tem sido decisiva para a cristalização dessa visão, tendo em vista: a forma fracionada e disciplinar com a qual aborda o conhecimento tanto do corpo, quanto da ciência; o engessamento em práticas pedagógicas que concebem o corpo como recipiente de informações; a aplicação de mecanismos de controle do corpo, impressos em padrões de comportamento; a supervalorização do intelecto e a negação e imobilização do corpo.

Para Ahlert (2011, p. 234) "superar essa realidade fragmentária de corpo herdada da Modernidade ainda se coloca como um desafio fundamental em todo o processo educativo". No entanto, o movimento de superação dessa conjuntura inicia no compromisso que a escola precisa tomar para si em relação a sua condição de influenciadora direta na produção de experiências, percepções e sentidos que são atribuídos ao corpo, de forma particular e ao mundo, de maneira geral.

Nóbrega (2005) aponta que as significações que surgem, os sentidos que atribuímos, são frutos de significações vividas, portanto, são marcas corporais que imprimem sentidos aos processos cognitivos de apreensão do mundo. Por esta razão, a escola como espaço privilegiado de ação e reflexão, precisa proporcionar experiências que se direcionem à compreensão do corpo, não como uma justaposição de partes distintas, ou uma configuração de um espírito senhor do corpo, mas sim como a própria expressão da corporeidade.

\begin{abstract}
A busca por uma compreensão do corpo além da visão dualista que historicamente delegou ao corpo a condição de instrumento em relação à mente e/ou alma, aponta o estudo da corporeidade como concepção que restitui a unidade corpórea, ou seja, a relação do corpo com o mundo e a indivisibilidade corpo-mentealma (FREIRE; DANTAS, p. 151, 2012).
\end{abstract}

Corroborando com esta concepção, acreditamos que é na corporeidade que encontramos subsídios epistemológicos para superar uma racionalidade mecanicista que, em nome do progresso, empurrou-nos a uma crise civilizatória de proporções imensuráveis, levando o ser humano a 
subjugar a natureza e a si mesmo, por meio de processos de dominação e poder.

A corporeidade, como aponta Nista-piccolo e Moreira (2012) é mais que um conceito, é uma atitude perante a vida e o mundo e, por esta razão nos encaminha para a liberdade de pensar e agir no mundo e com o mundo, conscientes das consequências deste pensar e agir.

\section{CONCLUSÃO}

Ao realizarmos uma incursão panorâmica sobre as unidades de significado que emergiram nesta investigação é possível observar claramente que os significados atribuídos ao corpo, pelos alunos do $6^{\circ}$ ano do Ensino Fundamental maior da Escola de Aplicação da Universidade Federal do Pará, estão imbricados com uma noção de corpo instrumental e fragmentado.

A visão reducionista do corpo, entendido unicamente por suas funções biológicas ou por sua condição reprodutora, nega a complexidade de nossa constituição como seres plenamente biológicos e culturais, restringe nossa subjetividade, nossas formas de ser e estar no mundo, por meio de nossa identidade individual e social tão diversa e rica.

Já diante do entendimento de corpo como morada da alma, acreditamos que este sim, encarcera nossa existência em uma subserviência tacanha, que não atinge as dimensões e possibilidades do corpo. Em contrapartida, quando nos deparamos com o sentido de movimento, mesmo que ainda com um pé na instrumentalidade, observamos um horizonte se abrindo para a corporeidade. Ao defender a corporeidade, manifestada em processos educativos humanizados, buscamos o encontro da educação e da instituição escola com a abrangência de sua função social.

Palcos (1988) adverte que o crescimento harmônico das crianças é substancialmente prejudicado quando são impostas travas em sua forma de se movimentar. Desta forma perguntamos: de que forma a escola, enquanto 
espaço de educação integral, está contribuindo para evitar que esse sistema de travas ao movimento das crianças seja eliminado? De que forma a educação física escolar vem contribuindo para a (re)construção da liberdade e da confiança da criança em seu próprio corpo, haja vista ela estar imbricada ao sentimento de confiança na vida?

Sugerimos a corporeidade como caminho de reconstrução da liberdade e da confiança no corpo e na vida, que ao longo do tempo as crianças vêm perdendo pelos travamentos a que seu corpo é submetido. Para Ahlert (2010, p. 117) "corporeidade vem de corpo, que é relativo a tudo que preenche espaço e se movimenta, e que ao mesmo tempo, localiza o ser humano como um ser no mundo", mostrando o corpo em sua natureza e essência.

$\mathrm{Na}$ corporeidade encontramos a possibilidade de ampliar as experiências e sentidos do corpo, de transcender todas as formas e possibilidades - que o marcaram negativamente, como a negação do corpo sujeito referendada pela teoria cartesiana (MOREIRA; SIMÕES; MURIA, 2009) - tanto individuais, quanto coletivas, colocando literalmente em movimento a condição complexa de nossa humanidade, que não entende o corpo fora de seu contexto; que ao interrogar a condição humana questiona, ao mesmo tempo, sua posição no mundo. Assim,

O sentido de corporeidade nos remete ao mundo de novas percepções que deverão substituir visões antigas. A corporeidade é um corpo engendrando vida, experienciando, vivenciando, na perspectiva humana, a caminhada em direção ao mundo (MOREIRA; SIMÕES; MURIA, 2009, p. 42).

A corporeidade, maneira como o ser humano se diz de si mesmo e se relaciona com o mundo e com o seu corpo enquanto objetividade (matéria) e, subjetividade (espírito, alma) num contexto de inseparabilidade, é uma luz que precisa transpor os muros ideológicos da escola. Assim, "as novas gerações precisam reencontrar o humano. Esse é o desafio da educação no século XXI". E para isso, "a educação deve compreender esse ser humano em sua complexidade caracterizada no corpo" (AHLERT, 2010, p. 123). 


\section{REFERÊNCIAS}

AHLERT, A. Corporeidade e educação: o corpo e os novos paradigmas da complexidade. Espacios en Blanco Revista de Educación, Universidad Nacional del Centro de la Provincia de Buenos Aires, Argentina, n. 21, p. 219240, jun. 2011. Disponível em: http://www.redalyc.org/articulo.oa? id=384539803009. Acesso em: 20/01/2017.

BARBOSA, M. R.; MATOS, P. M.; COSTA, M. E. Um olhar sobre o corpo: o corpo ontem e hoje. Psicologia e Sociedade, Minas Gerais, n. 23, p. 24-34, 2011. Disponível em: http://www.scielo.br/pdf/psoc/v23n1/a04v23n1.pdf. Acesso em: 10/03/2017.

BRASIL, MINISTÉRIO DA EDUCAÇÃO. Parâmetros curriculares nacionais. Educação Física: Ensino Fundamental, $3^{\circ}$ e $4^{\circ}$ ciclos. Brasília: MEC/SEF, 1998.

BRASIL. Ministério da Educação. Base Nacional Comum Curricular. Proposta preliminar. $3^{a}$ versão revista. Brasília: MEC, 2017.

CAMPOS, S. L. de B. O materialismo no pensamento de Santo Tomás. Revista Notandum, Universidade do Porto, Portugal, n. 15, p. 47 - 54, jan. 2007. Disponível em: http://www.hottopos.com/notand15/savio.pdf. Acesso em: 10/03/2017.

CAPRA, F. O ponto de mutação. São Paulo: Cultrix, 1993.

CASSIMIRO, E. S.; GALDINO, F. F. S.; MATEUS DE SÁ, G. As concepções de corpo construídas ao longo da história ocidental: da Grécia antiga à contemporaneidade. Revista Eletrônica Print, São João Del Rei, n.14, p. 61-79, $2012 . \quad$ Disponível em: https://ufsj.edu.br/portal2repositorio/File/revistalable/4_GERALDO_CONFERIDO.pdf. Acesso em: 15/10/2016.

COSTA, V. M. M. Corpo e história. Revista Ecos, Mato Grosso, n. 10, p. 245-258. Jul. $2011 . \quad$ Disponível em: http://www.unemat.br/revistas/ecos/docs/v_10/245_Pag_Revista_Ecos_V10_N-01_A-2011.pdf. Acesso em: 15/10/2016.

CSORDAS, T. J. Embodiment as a paradigm for anthropology. Ethos, Estados Unidos, v. 18, n. 1, p. 5-47, março, 1990. Disponível em: http://onlinelibrary.wiley.com/doi/10.1525/eth.1990.18.1.02a00010/abstract. Acesso em: 12/01/2015.

DAOLIO, J. Da cultura do corpo. 13a ed. Campinas: Papirus, 2009.

FARAH, M. H. S. O corpo na escola: mapeamentos necessários. Paidéia, Ribeirão Preto, v. 20, n. 47, p. 401-410 set-dez. 2010. Disponível em: http://www.scielo.br/pdf/paideia/v20n47/a12v20n47.pdf. Acesso em: 27/04/2016.

FERRACINI, R. Café com queijo: corpos em criação. São Paulo: Hucitec, 2006. 
FERREIRA, F. R. A produção de sentidos sobre a imagem do corpo. Interface Comunicação, Saúde e Educação, v. 12, n. 26, p. 471-483, jul./set. 2008. Disponivel em: http://www.scielo.br/pdf/icse/v12n26/a02.pdf. Acesso em: 15/03/2017.

FREIRE, I. M; DANTAS, M. H. de A. Educação e Corporeidade: um novo olhar sobre o corpo. Revista HOLOS, Rio Grande do Norte, a. 28, v. 4, p. 148-157, set. 2012. http://www2.ifrn.edu.br/ojs/index.php/HOLOS/article/view/729/578. Acesso em: 22/03/2017.

FOULCAULT, M. Vigiar e punir: nascimento da prisão. $42^{a}$ ed. Petrópolis: Vozes, 2014.

GAYA, A. Será o corpo humano obsoleto? Sociologias. a. 7, n. 13, p. 324-337, jan./jun. 2005. Disponível em: http://www.scielo.br/pdf/soc/n13/23566.pdf. Acesso em: 12/03/2017.

GEERTZ, C. A interpretação das culturas. Rio de Janeiro: LTC, 2008.

INFORSATO, E. do C. A educação entre o controle e a libertação do corpo. In: MOREIRA, W. W. (org.) Século XXI: a era do corpo ativo. Campinas: Papirus, p. 91-108, 2006.

LE BRETON, D. A sociologia do corpo. $3^{a}$ ed. Petrópolis: Vozes, 2009.

LOURO, G. L. Corpo, escola e identidade. Revista Educação e Realidade, Rio Grande do Sul, n. 25, v. 2, p. 59-76, jun./dez, 2000a. Disponível em: http://www.seer.ufrgs.br/educacaoerealidade/article/viewFile/46833/29119. Acesso: 20/04/2017.

LOURO, G. L. O corpo educado: pedagogias da sexualidade. $2^{a}$ ed. Belo Horizonte: Autêntica, 2000b.

MENDES, M. I. B. de S. Corpo, biologia e educação física. Revista Brasileira de Ciências do Esporte, Campinas, v. 24, n. 1, p. 9-22, set. 2002. Disponível em: http://www.revista.cbce.org.br/index.php/RBCE/article/view/337. Acesso em: 10/12/2016.

MOREIRA, W. W.; SIMÕES, R.; PORTO, E. Técnica de elaboração e análise de unidades de significado. Revista Brasileira de Ciência e Movimento, Brasília, v. 13, n. 4, p.107-114, out/dez, 2005. Disponível em: https://portalrevistas.ucb.br/index.php/RBCM/article/view/665. Acesso em: 20/12/2016.

MOREIRA, W. W.; SIMÕES, R.; MURIA, A. J. O fenômeno corporeidade na formação profissional em educação física: a perspectiva docente. In: MOREIRA, W. W.; SIMÕES, R. (orgs.) Educação física e produção de conhecimento: corporeidade, esporte, lazer, saúde. Belém: EDUFPA, p. 37-52, 2009.

MORIN, E. Os sete saberes necessários para a educação do futuro. $2^{a}$ ed. São Paulo: Cortez, 2011. 
NEVES, J. L. Pesquisa qualitativa: características, uso e possibilidades. Cadernos de pesquisa em adminsitração, São Paulo. V. 1, n 3, $2^{\circ}$ sem. 1996.

NISTA-PICCOLO, V. L.; MOREIRA, W. W. Esporte para a saúde nos anos iniciais do Ensino Fundamental. São Paulo: Cortez, 2012a.

NISTA-PICCOLO, V. L.; MOREIRA, W. W. Esporte para a vida no Ensino Médio. São Paulo: Cortez, 2012b.

NÓBREGA, T. P. da. Qual o lugar do corpo na educação? Notas sobre conhecimento, processos cognitivos e currículo. Revista Educação e Sociedade, Campinas, v. 26, n. 91, p. 599-615, Maio/Ago. 2005. Disponível em: http://www.scielo.br/scielo.php?.pid=\$0101-

73302005000200015\&script=sci_abstract\&tlng=pt. Acesso em: 13/01/2017.

NÓBREGA, T. P. da. Uma Fenomenologia do corpo. São Paulo: Livraria da Física, 2010.

OLIVEIRA, M. A. T. de. Educação do corpo na escola brasileira. Campinas: Autores Associados, 2006.

PALCOS, M, A. Corpo e psiquismo. Rio de Janeiro: Espaço Coringa, 1998.

PENA, A.; BOGÉA, I. C.; BORGES, L. P. Aconchegando o corpo na escola: as perspectivas. In: TV Escola. Salto pata o futuro: o corpo na escola, Ministério da Educação, Brasília, a. XVIII, n. 4, p. 41-52, abr. 2008. Disponível em: http://canbi.tvescola.org.br/resources/VMSResources/contents/document/p ublicationsSeries/181924Corponaescola.pdf. Acesso em: 20/12/2016.

PICHLER, N. A. A natureza da alma intelectiva em Tomás de Aquino. Revista Intuitio, Rio Grande do Sul, v. 1, n. 2, p. 257-273, 2008. Disponível em: http://revistaseletronicas.pucrs.br/ojs/index.php/intuitio/article/view/4002.

Acesso em: 10/03/2017.

PIRATELI, M. R. O conceito de Homem em Santo Agostinho. In: VIII Jornada de Estudos Antigos e Medievais \& I Jornada Internacional de Estudos Antigos e Medievais, Anais da Jornada de Estudos Antigos e Medievais, Maringá, p. 115 2009. Disponível

em: http://www.ppe.vem.br/jeam/anais/2009/pdf/66.pdf. Acesso em: 20/01/2017.

PINHEIRO, J. da S. A Experiência do Ser Humano Cartesiano. Trilhas Filosóficas, Rio Grande do Norte, v. 4, n. 1, p. 50-64, 2011. Disponível em: http://periodicos.uern.br/index.php/trilhasfilosoficas/article/view/621. Acesso em: 20/12/2016.

PROBST, M.; KRAEMER, C. Sentado e quieto: o lugar do corpo na escola. Atos de Pesquisa em Educação, Blumenau, v. 7, p. 507-519, mai./ago. 2012. Disponível em: http://proxy.furb.br/ojs/index.php/atosdepesquisa/article/view/3163. Acesso em: 20/01/2017.

QUADRADO, R. P.; RIBEIRO, P. R. C. O corpo na escola: alguns olhares sobre o currículo. Enseñanza de las Ciencias, n. extra, p. 1-4, 2005. Disponível em: 
http://portfolio.unisinos.br/OA12/pdf/Corpo_na_Escola.pdf.

Acesso: 10/05/2017.

RIBEIRO, A. O corpo que somos: aparência, sensualidade, comunicação. Lisboa: Editorial Notícias, 2003.

SANT'ANNA, D. B. É possível realizar uma história do corpo? In: SOARES, C. L. (Org.). Corpo e História. Campinas: Autores Associados, $2^{a}$ ed. 2004.

RODRIGUES, D. Os valores e as atividades corporais. São Paulo: Summus, 2008.

SILVA, D. da. O pecado original: raízes histórico-teológicas de uma controvérsia. Revista de Cultura Teológica, São Paulo, v. 17, n. 66, jan./mar. 2009.

em:

https://revistas.pucsp.br/index.php/culturateo/article/view/15492. Acesso em: 10/01/2017.

TIRIBA, L. Proposta pedagógica. In: TV Escola. Salto pata o futuro: o corpo na escola, Ministério da Educação, Brasília, a. XVIII, n. 4, p. 41-52, abr. 2008. Disponível em: http://cdnbi.tvescola.org.br/resources/VMSResources/contents/document/p ublicationsSeries/181924Corponaescola.pdf. Acesso em: 20/12/2016.

STOROLLI, W. M. A. O corpo em ação: a experiência incorporada na prática musical. Revista da ABEM, Londrina, v.19, n. 25, p. 131-140, jan./jun. 2011. Disponível em:

http://www.abemeducacaomusical.com.br/revistas/revistaabem/index.php/ revistaabem/article/view/196. Acesso em: 20/12/2017.

Recebido em: Agosto de 2017 Aprovado em: Dezembro de 2017 